Revista Iberoamericana, Vol. LXIX, Núm. 205, Octubre-Diciembre 2003, 839-848

\title{
MULTITUD, DEVENIRES Y ÉXODO: LA ÚLTIMA CENA DE TOMÁS GUTIÉRREZ ALEA
}

POR

\author{
Juan Antonio HeRnÁndez \\ University of Pittsburgh
}

En “Calibán después del comunismo”, John Beverley discute la posibilidad de extraer de la lógica del multiculturalismo un principio igualitario radical que permita repensar el proyecto de la izquierda en tiempos de hegemonía neoliberal. Tras hacer la crítica de las teorías de la transculturación y de la hibridez, Beverley retoma la concepción de una "heterogeneidad no dialéctica"-elaborada originalmente por Cornejo-Polar-para colocarla en relación con un tipo de sujeto social multiforme, heterogéneo, definido por Virno como “multitud” o por Lyotard como lo “pagano”. Los rostros del “nuevo Calibán” serían, para usar el titulo del hermoso libro de Linebaugh y Rediker, los de la "hidra de múltiples cabezas”. ${ }^{1}$

Quisiera situar mi reflexión sobre La última cena de Tomás Gutiérrez Alea en relación con lo anterior, intentando atisbar en ella elementos que posibiliten pensar la emergencia, en el presente, del “nuevo Calibán”. Se trata de revisitar esta película explorando ciertas fisuras, ciertas zonas de indiscernibilidad que permitirían una lectura a "contrapelo" de la lógica de la transculturación, estableciendo, a partir de sus imágenes, líneas de fuga en relación con el aparato de captura, homogeneizador de la diferencia cultural, conformado por la ideología del Estado nacional cubano. Para ello utilizaremos, libremente, tres nociones provenientes de la reflexión teórica de Deleuze, Virno y Negri: devenir minoritario, multitud y éxodo, procurando llevar la película de Gutiérrez Alea más allá de la dialéctica hegeliana en la que tradicionalmente ha sido inscrita.

I. CimARRONISMO y LímiteS DE LA TRANSCULTURACióN

Diversos críticos han destacado que la idea de transculturación depende de un historicismo de origen hegeliano en el que la formación del Estado nacional es concebida

\footnotetext{
${ }^{1}$ Aludimos a The Many-Headed Hydra: Sailors, Slaves, Commoners, and the Hidden History of the Revolutionary Atlantic. Se trata de una historia de la multitud, en el contexto del Atlántico Norte, entre los siglos XVII, XVIII y XIX. El libro reconstruye un sujeto social, subalterno y multiétnico, en estado de permanente rebelión contra los sectores dominantes de la época, quienes bautizaron a esta multitud con el nombre de "hidra”, aludiendo al conocido monstruo de la mitología greco-latina para describir el carácter temible de dicha fuerza social.
} 
como resultado de un proceso teleológico de síntesis de las diferencias culturales. ${ }^{2}$ En relación con esto, habría que repensar el vínculo de La última cena con la dialéctica del amo y el esclavo, relación que podría prestarse, desde cierta ideología del mestizaje, para analogar los procesos de transculturación con la reconciliación o síntesis final que, de acuerdo con Hegel, habría de producirse entre siervo y señor.

Obviamente el miedo a la muerte se encuentra, como momento de violencia fundante o de acumulación política primitiva, presupuesto en las diversas interacciones entre el Conde y la mayor parte de sus esclavos durante la secuencia central del filme. Sin embargo, cabría destacar la superación del temor a la muerte -causa última del sometimiento del esclavo en la narrativa hegeliana- en la famosa secuencia en que el personaje del cimarrón escupe el rostro del Conde y se niega a hablar en su presencia. Sebastián representaría, de este modo, un momento de negatividad radical, de superación de la dialéctica entre amo y esclavo lo cual, si nuestra lectura es correcta, implicaría una fisura en el historicismo que conduce a la fundación del Estado nacional cubano. Y es que el Estado, desde la perspectiva de Hegel, sería el lugar de institucionalización del pacto que “pacificaría” la violencia fundante, de lucha a muerte por el reconocimiento, entre las autoconciencias del amo y el siervo. El cimarrón sería la condensación metafórica de una diferencia irreductible. Dicha negación radical se encuentra, según creo, en articulación directa con un fantasma que recorre toda la atmósfera histórica que intenta reconstruir la película: el temor a la rebelión de la multitud, evocada en las referencias al levantamiento de los esclavos en Haití. El cimarrón de la película sería, como hemos dicho, la metáfora de una grieta que no puede ser llenada por el discurso transculturador, una ideología de la modernidad que en el momento mismo de su producción, en Cuba, aparece asediada por el trauma social de otro levantamiento de negros rebeldes: el de los ex-combatientes de la guerra de independencia cubana en 1912 (Beverley, Subalternity 45). Como sabemos, ya que ha sido ampliamente estudiado, esta insurrección y su posterior aplastamiento resultan elementos históricos suprimidos de la edición del célebre testimonio de Esteban Montejo Biografía de un cimarrón.

En La última cena, la metaforización del blanqueamiento y del mestizaje se produce en el relato de la elaboración del azúcar refinada a partir de la melaza negra, hecho por Don Gaspar, el químico mulato que ha escapado del Haití controlado por los negros sublevados y quien se encuentra a la cabeza de la modernización del proceso productivo del ingenio. Don Gaspar describe el proceso en términos claramente teleológicos: "lo destinado a blanco ha de ser primero negro”, dice en el diálogo con el cura, el Conde y el mayoral, describiendo, irónicamente, la refinación del azúcar como análoga a la purificación de las almas en el purgatorio. La réplica del cura,"desdichadamente no todas las almas se purifican en el purgatorio”, es complementada por el técnico con una metáfora que se refiere claramente al mestizaje: “No todo el guarapo se puede convertir en blanca azúcar”,

\footnotetext{
2 John Beverley apunta sobre este particular lo siguiente: "For both Rama and Ortiz transculturation functions as a teleology, not without marks of violence and loss, but necessary in the last instance for the formation of the modern nation-state and a national (or continental) identity that would be something other than the sum of its parts, since the original identities are sublated in the process of transculturation itself” (Subalternity 45).
} 
lo cual resulta una obvia referencia intertextual a las metáforas utilizadas por Ortiz para hablar de los procesos de mestizaje transculturador en Cuba. ${ }^{3}$

Luego del uso de las metáforas de blanqueamiento y mestizaje, aparece la necesidad de aumentar la producción y el eventual requerimiento de mayor cantidad de mano de obra esclava. Ante esto, el técnico expresa su temor de que los negros aventajen en número a los blancos y mulatos, tal como ocurrió en el Haití pre-revolucionario. La película coloca las metáforas de blanqueamiento y mestizaje antes de la evocación de la revolución haitiana y de la presencia del cimarrón, lo cual produce, según creo, una línea de fuga que permite pensar la representación del cuerpo de Sebastián como metonimia del cuerpo de la multitud de los esclavos sublevados en Haití y, potencialmente, en Cuba. Para decirlo de otro modo, el relato del blanqueamiento y del mestizaje resulta interrumpido, precisamente, por la amenaza de la revolución haitiana y esta alusión es conectada directamente con la presencia del cuerpo del cimarrón.

En relación con la crítica de la transculturación y el mestizaje, resulta central pensar el relato del cimarrón durante la cena. La violencia originaria, narrada como lucha entre "Verdad” y "Mentira”, termina produciendo un cuerpo híbrido, grotesco, "transculturado": la Verdad con la cabeza de la Mentira. Nos hallamos, evidentemente, ante una compleja renarración de la dialéctica del amo y el esclavo. En ella el esclavo, o el cuerpo de la "Verdad”, parecería condenado a necesitar de la cabeza del amo, o lo que es lo mismo, de los valores o la cultura de una autoconciencia enajenada de la materialidad del mundo y del trabajo. El rechazo a esta forma de "transculturación” estaría representado en el momento final del relato del cimarrón, cuando éste coloca la cabeza de cerdo enfrente de su propia cabeza. El gesto de Sebastián de arrojarle a Antonio, el esclavo servil, la cabeza de cerdo expresaría, simultáneamente, un rechazo radical del dualismo cuerpo-espíritu -contenido en la imagen “transculturada” de la Verdad con la cabeza de la Mentira- el cual es también, por supuesto, parte constituyente de la ideología católica y esclavista.

Por otra parte, habría que explorar con más detenimiento la posible relación metonímica entre el cuerpo del cimarrón y el de la multitud. Adelantándome un poco a mi lectura de los devenires en la película, quisiera recordar que, para Deleuze y Guattari, todo devenir es rizomático en el sentido de articular el cuerpo que deviene con una multiplicidad abierta, en una relación que muestra una zona de contacto entre deseo y poder. Dicha zona expresa, en términos spinozianos, la capacidad que posee un cuerpo de afectar y de ser afectado por otros cuerpos, por lo que "nadie sabe lo que puede un cuerpo", para recordar el famoso aforismo del judío holandés. Si la fuga de Sebastián, al final de la película, puede leerse en relación con los devenires, tendríamos entonces un cuerpo abierto a las fuerzas deseantes, constituyentes, que integrarían el cuerpo colectivo de la multitud. En el capítulo "The Body of the Multitude" de su libro Bodies, Masses, Power: Spinoza and his contemporaries, Warren Montag ha reconstruido las contradicciones y aporías que en el

\footnotetext{
${ }^{3}$ Escogiendo solo uno entre múltiples y conocidos ejemplos, recogemos la siguiente cita de Ortiz: "El azúcar cambia de coloración, nace parda y se blanquea; es almibarada mulata que siendo prieta se abandona a la sabrosura popular y luego se encascarilla y refina para pasar por blanca, correr por todo el mundo, llegar a todas las bocas y ser pagada mejor, subiendo a las categorías dominantes de la escala social" (6).
} 
pensamiento de Spinoza produjo el vínculo entre democracia absoluta y multitud. Spinoza, de acuerdo con Montag, no habría podido extraer todas las consecuencias políticas de la relación entre multitud, deseo y poder, al excluir de la práctica de la democracia absoluta a las mujeres y a los siervos (85-6), lo cual sería parte de un temor a las masas, generalizado en los pensadores de la época y que constituiría uno de los rasgos fundantes de la filosofía política moderna. Precisamente, para Montag, serían los esclavos el referente clave del pensar spinoziano en torno a la multitud:

\begin{abstract}
Spinoza's work from beginning to end remains haunted by figures of the inassimilable, the exceptions to the democracy without exceptions, and simultaneously by the impossibility of their exclusion.

Indeed, it is testimony to the power of Spinoza's thought, precisely a thought that renounces all forms of transcendence to take power at its object, that no obstacle (including and especially those erected by Spinoza himself) can withstand its force as it moves to towards absolute democracy. If, as Balibar [...] has insisted, the figure of woman in the Tractatus Politicus functions as a metonymic substitution for the masses, the plebs, we must follow the logic of Spinoza's argument to its conclusion and include among its referents those on the margins of margins: slaves. (86-7)
\end{abstract}

Montag prosigue su argumento mostrando la presencia de la lucha de los negros cimarrones en América en el imaginario que subyace a la teoría política de la multitud elaborada por Spinoza. Por ello, si en el contexto caribeño colonial la identidad de la multitud se encuentra sobredeterminada por los cuerpos de los esclavos de los ingenios y haciendas, quizás no sea del todo aventurado leer a Sebastián como metonimia de esa multitud.

Pero esta interpretación nos conduce a plantearnos el problema de los límites de la representación de la multitud negra en la película. ${ }^{4}$ Resulta evidente, por ejemplo, que la diferencia de género no se encuentra representada suficientemente en La última cena. Las alusiones a la mujer esclava son limitadas y se encuentran, por ejemplo, expresadas en la interpelación del cura a las que lavan la ropa en el río, con los pechos desnudos, como "pecadoras", etc. Esto que resulta ridiculizado en la risa de los esclavos, tras caer el sacerdote al agua, se encuentra reformulado, más adelante, en la secuencia de la cena, al referirse el Conde a Eva y al pecado original. La risa del Conde y de los esclavos, al narrar el mito de la manzana de la tentación, establece una relación de complicidad masculina que solo es fisurada por la imperturbabilidad de Sebastián, quien es el único que no celebra la narración del amo. Sin embargo, esta no participación del cimarrón en las risas que siguen al relato de Eva resulta insuficiente, a su vez, si colocamos su figura en relación con cierta épica masculina, del “viejo Calibán”, elaborada en el discurso oficial de la Revolución cubana por Fernández Retamar. Sobre este punto volveremos más adelante.

\footnotetext{
${ }^{4}$ Aunque quizás podríamos destacar las breves alusiones a la heterogeneidad cultural de los diversos grupos subsumidos bajo la identidad del "negro” o "esclavo”, al aparecer en la película menciones a los “congos”, "lucumi”, "carabali”, etc.
} 


\section{UsOS DE LOS SÍMBOLOS RELIGIOSOS}

La secuencia de la cena muestra la imposibilidad de imponer una interpretación única a los símbolos centrales del catolicismo: la eucaristía, el Paraíso terrenal, la figura de Cristo y los apóstoles, etc. De hecho, toda la escena -con la sola excepción del relato del cimarrón- podría leerse como una negociación por el significado, entre amo y esclavos, de tales símbolos. Esto, sin duda, estaría conectado con la reflexión que la película propone en torno a la transculturación. Si la negociación entre amo y esclavos sobre el sentido de los símbolos católicos puede leerse como una metáfora sobre la transculturación, entonces, como hemos visto, el relato del cimarrón sobre Olofi, la Verdad y la Mentira, queda del lado de un pensar y afirmar la diferencia en cuanto diferencia. ${ }^{5}$

Desde la perspectiva de la ideología esclavista, hallamos las analogías que el Conde intenta imponer entre su figura y la de Cristo. Así, por ejemplo, en una cena expresa: "Un día como hoy... Cristo se reunió con sus amigos, los santos... sus discípulos que eran como... sus esclavos... Cristo iba a morir...” El esclavo, por su parte, responde: “No, no, mi amo no se puede morir...mi amo es muy bueno...”. Este corto intercambio muestra uno de los aspectos más frecuentes en la construcción de los diálogos entre esclavos y amo en la película: la tensión entre metaforicidad y literalidad al referirse a los símbolos católicos.

Quizás el momento más evidente de esta tensión sea el de la interpretación literal de la eucaristía, por parte de los esclavos, como un acto de canibalismo. Dicha interpretación hace que Ambrosio señale a un “carabali” como parte de una supuesta etnia caníbal, lo cual provoca en el amo un intento nervioso de volver a colocar en un plano metafórico la idea de la comunión.

Al mismo tiempo, los intentos de identificación literal entre el Conde y Cristo presentan momentos de crisis, de fisura, como en la secuencia en la que el amo describe la Pasión y habla de la corona de espinas colocada alrededor de la cabeza de Jesús. El Conde, en el momento preciso en que esta narrando esta fábula, se detiene a mirar, perturbado, la cabeza herida y vendada del cimarrón, tras lo cual se produce un intercambio de miradas entre el amo y Sebastián. Todo esto provoca una vacilación en la analogía intentada por el Conde del martirio cristiano. El vínculo metafórico entre el amo y Cristo parecería, de este modo, quebrantarse para desplazarse hacia una analogía entre Cristo y el cimarrón.

La negociación o disputa por la interpretación aparece expresada, con igual intensidad, en la reacción de los esclavos al terminar la parábola del amo sobre la humildad de San Francisco. La risa de los negros -para los cuales hallar la felicidad en la aceptación del

\footnotetext{
${ }^{5}$ Todo esto resulta, sin duda, mucho más complejo, si pensamos en la secuencia en que el cura y el amo discuten sobre el significado que los esclavos podrían atribuirle a la representación de la última cena. Nos referimos a la parte final de la película, poco antes de que estos personajes conozcan la noticia de la rebelión. Mientras el Conde sostiene que los esclavos han comprendido los símbolos del catolicismo como una invitación a la resignación y a la humildad, el cura, significativamente, sugiere la posibilidad de que los esclavos hayan aprendido una cosa muy diferente: la posibilidad de "sentarse a la mesa del señor", de igualarse al amo. Esta sugerencia reconocería la posibilidad de una especie de "transculturación al revés”, en la que se produciría una apropiación subalterna de los signos que la dominación intenta imponer.
} 
dolor solo puede ser un chiste- es seguida por una serie de preguntas sobre la resignación: “¿por qué el mayoral no coge golpes también?” Esto será respondido por el amo con la apelación exaltada a la obediencia incontestable de los designios divinos y con la descripción del premio del paraíso celestial.

Un aspecto central del uso de los símbolos religiosos -y particularmente de las metáforas referidas al sacrificio y al cielo- tiene que ver, directamente, con la relación de la película con el referente inmediato de la Revolución cubana, el historicismo de ésta, orientado radicalmente hacia el futuro, y la austera ideología del Hombre Nuevo. En una entrevista con Martha Ansara, Gutiérrez Alea hace explícito este aspecto de su película:

La última cena es una película metafórica basada en acontecimientos reales, narrados a modo de parábola. Aborda el hecho de cómo puede ser manipulada una ideología que representa valores éticos -la ideología cristiana por ejemplo. Todas las ideologías religiosas y políticas representan valores morales, éticos, pero una ideología puede ser distorsionada desde el momento en que comienza a volverse contra sí misma. [...] En todas partes hay gente que asume el comunismo como una religión. Creo que es funesto, porque así empiezan a distorsionar su sentido. Quizás La última cena contribuya a hacerlo entender. (Citado por Evora, 43-4)

Desde esta perspectiva, el paternalismo del Conde podría ser una alusión, más o menos encubierta, al liderazgo de Fidel Castro y al discurso oficial que exige permanentes sacrificios a las masas cubanas. En todo caso, la ideología del sacrificio, orientada teleológicamente hacia un futuro paradisíaco, no deja de mostrar, también, las semejanzas entre los discursos historicistas, de modernidad y progreso, característicos tanto de las sociedades capitalistas como de aquellas inscritas en los procesos conocidos como "socialismo real".

Un elemento ambiguo para nuestra interpretación de Sebastián en tanto posible metonimia de la multitud es la metáfora de resurrección que aparece sugerida al final de la película, luego del sacrificio de los once esclavos por parte de los “rancheadores" del Conde. Sabemos, por los carteles que dividen temporalmente las acciones del filme, que el discurso final del amo, rodeado por las picas con las cabezas cortadas de sus esclavos, se produce en el "domingo de resurrección” de la Semana Santa. El plano general de los doce postes es seguido por una iluminación difuminada que nos conduce hacia el bosque donde se produce la fuga del cimarrón. Todo esto pareciera indicar que los once esclavos sacrificados resucitan en la imagen del cuerpo en fuga de Sebastián. Si esto es cierto, ello reintroduciría la idea de una síntesis final que subsumiría las diferencias que constituyen a la multitud. Quizás esto tendría que ver, además, con la relación del personaje de Sebastián con la épica del “viejo Calibán” a la que me referí al comienzo de este ensayo. Desde esta perspectiva, el cimarrón resultaría análogo al héroe de la lucha armada, en tanto culminación hegeliana de una autoconciencia surgida del rechazo absoluto a la dominación. Esto, sin duda, entraría en tensión con el principio radicalmente igualitario de la multitud, ya que sería la expresión metafórica del típico vanguardismo heroico, propio de la ideología cubana de los sesenta y setenta. Y, precisamente, si algo opone la multitud al vanguardismo son las nociones de poder constituyente e intelectualidad de masas inscritas 
en la idea misma de multitud. ${ }^{6}$ El cierre de la película, con la imagen solitaria del Cimarrón, subiendo hacia la cumbre de la montaña, reforzaría, sin duda, la presencia de la ideología del "Hombre Nuevo" en el filme. Por ello, para problematizar esta posible clausura épica, quisiera colocar la fuga final en relación con las nociones de devenir y éxodo.

\section{Devenires, MUltitud y ÉXodo}

Quizás el contexto inmediato de producción de la película-la institucionalización del proceso revolucionario, la renuncia a expandir la revolución hacia Latinoamérica y la participación de tropas cubanas en Angola- podría servirnos como punto de partida para pensarla como una obra situada entre la territorialización y la desterritorialización de las fuerzas, sociales y políticas, que produjeron a la propia revolución. Así, mientras las fuerzas de territorialización procuran inscribir a La última cena en un gesto genealógico por "restituir la verdadera imagen del esclavo en nuestra historia y revelar el vital aporte que la presencia africana ha brindado a la formación de nuestra cultura, identidad nacional y tradición de lucha por la independencia", 7 por otro lado, el movimiento de desterritorialización se afirmaría en la metáfora del éxodo del cimarrón, al final de la película. Quizás cabría agregar que estas fuerzas de territorialización y desterritorialización no solo se encuentran en el contexto inmediato de producción de la película. Formaron, a su vez, parte central de los eventos históricos que el filme se propone representar. Tal y como afirman Negri y Hardt en relación con la lucha de los esclavos en las Américas: "The deterritorializing desire of the multitude is the motor that drives the entire process of capitalist development, and capital must constantly attempt to contain it” (124).

Todo esto podría servir para pensar la tensión, a mi modo de ver todavía no resuelta, entre sujeto nacional-popular y multitud, en condiciones de globalización. En Empire, Negri y Hardt han optado, radicalmente, por afirmar el carácter desterritorializado de la multitud, planteando el cierre de las luchas de liberación nacional y, por tanto, el fin de un sujeto nacional-popular que resistiría a las formas ya desaparecidas del viejo imperialismo. Si la fuga de Sebastián puede leerse, desde nuestro presente, como una metáfora del éxodo de la multitud, habría que pensar en cómo hacer la crítica de la Revolución cubana sin incurrir en una especie de justificación etapista de la transición al neoliberalismo globalizado. No tengo respuestas para esto, tan solo apunto a una posible línea de reflexión a ser desarrollada en futuros trabajos.

\footnotetext{
${ }^{6}$ Virno y Hardt definen ambos términos de la siguiente manera: “Constituent power: This term refers to a form of power that continually creates and animates a set of juridical and political frameworks. Its perpetually open processes should be contrasted with the static and closed character of constituted power." "Mass intellectuality: This term refers to the collective intelligence and accumulated intellectual powers that extend horizontally across society. It does not refer to a specific group or category of the population [...] Intellectuality is not a phenomenon limited to the individual or the closed circle of trained intellectuals; it is a mass phenomenon that depends on a social accumulation and that proceeds through collective, cooperative practices” (260- 2).

7 Cita tomada del artículo de Carlos Galeano, "Para rescatar su verdadera imagen”, publicado originalmente en Granma, y recogido, posteriormente en el libro: Alea, una retrospectiva crítica, citado en la bibliografía de este ensayo.
} 
He sostenido que la representación metonímica de la multitud, a través del cuerpo en fuga de Sebastián, se encuentra relacionada con una noción de corporalidad, spinoziana y deleuziana, implícita en la idea de devenir minoritario o devenir otro. Ahora, brevemente, me referiré a la teorización de los devenires elaborada por Deleuze y Guattari para, finalmente, establecer la relación de la fuga del cimarrón con la idea de éxodo.

El devenir siempre establece una relación de contagio o de pacto con una multiplicidad. Este vínculo es una imbricación, un contacto, entre deseo y poder que permite la producción afectiva de un cuerpo transindividual o colectivo. Siempre se deviene "otro", se deviene algo inhumano o fuera de los procesos de subjetivación que producen lo humano. Se deviene animal, mujer, música, niño, negro, judío, revolucionario, multitud. En el caso del cimarrón de La última cena encontramos todo un flujo de devenires: Sebastián deviene pájaros, caballos, peces, en la secuencia final de la fuga. Como ya dije, estos devenires implican una noción de lo corporal que posibilitan pensar el cuerpo del cimarrón como abierto al devenir multitud y, por supuesto, al devenir máquina de guerra de la multitud:

Hay toda una política de los devenires-animales, como también hay una política de la brujería: esta política se elabora en agenciamientos que no son ni los de la familia, ni los de la religión, ni los del Estado. Mas bien expresarían grupos minoritarios, u oprimidos, o prohibidos, o rebeldes, o que siempre están en el borde de las instituciones reconocidas, tanto más secretos cuanto que son extrínsecos, en resumen, anómicos (Deleuze y Guattari, 252).

En la cita anterior “minoritario" refiere a un proceso de desterritorialización de los grupos oprimidos en relación con las instituciones propias de la dominación burguesa: el Estado, la familia, la religión (Patton 80-1). Además de esto, el fragmento anterior, de Mil mesetas, nos permite ver cómo los devenires animales, ligados a una "política de la brujería”, aparecen al final La última cena. ${ }^{8}$ Precisamente, en el diálogo del cimarrón con los otros esclavos, surge la mención de unos polvos con "poderes” para provocar los devenires: "Esta vez Sebastián sí tendrá con qué defenderse...estos son poderes míos... [saca la bolsa de cuero con polvos] con esto Sebastián se jace palo en los montes ... se jace pescao en los ríos... se jace piedra... se jace Zum Zum y ¡vuela!”.

Es en esta relación entre cuerpo, devenires, multiplicidad y multitud, donde he querido vislumbrar la posibilidad del "nuevo Calibán” en la película. Se trataría de la expresión metafórica de una posible articulación de afectos, de deseos, de cuerpos, de

\footnotetext{
${ }^{8}$ Esto serviría, además, para realizar un estudio comparativo entre la película de Gutiérrez Alea y El reino de este mundo de Alejo Carpentier, particularmente en torno a las analogías y diferencias entre Sebastián y Mackandal. Dennis West ha destacado este vínculo sin tomar en consideración el concepto de "devenir". West plantea que en Gutiérrez Alea opera una radicalización del realismo mágico de Carpentier: mientras en El reino de este mundo coexisten los puntos de vista de amos y esclavos en la valoración de la muerte o metamorfosis de Mackandal, en "La última cena” , de acuerdo con este crítico, solo se admite el punto de vista de los negros en relación con las metamorfosis "mágicas” de Sebastián (167-8).
} 
poder constituyente, en la que Michael Hardt encuentra, junto con John Beverley, la posibilidad de repensar el comunismo:

On the political horizon, the multiplicity of social practices and desires presents us with the conditions of composition or assemblage. This is the field on which the process must be defined: Assemblage must be pursued by bringing together social bodies with compatible internal relationships, with composable practices and desires. In the existing social practices, in the affective expressions of popular culture, in the networks of laboring cooperation, we should seek to discern the material mechanism of social aggregation that can constitute adecuate, affirmative, joyful relationships and thus powerful subjetive assemblages. Filling out the passage from multiplicity to multitude remains for us the central project for a democratic political practice. (Hardt 122)

Para concluir, me gustaría tan solo destacar las posibles relaciones entre cimarronismo y “éxodo”, siendo este último concepto una radicalización del "rechazo al trabajo”, teorizado, entre otros, por Paolo Virno y Antonio Negri. De acuerdo con la noción de "éxodo", las estructuras de dominación sobre el trabajo y la vida pueden ser combatidas por los sujetos sociales subalternos no a través de una confrontación directa, sino por medio de la fuga o retirada de los espacios controlados por tales estructuras de dominación. Se trata de minar las bases de sustentación del Estado y del mando capitalista a través de la retirada de la multitud en un proceso de autovaloración y de afirmación del poder constituyente. Me gustaría pensar que, por ello mismo, La última cena concluye en la fuga, en las líneas de fuga que podrían conectar la imagen del cimarrón con el "nuevo Calibán”, con las reales y potenciales insurgencias de la multitud en el presente.

\section{BiBLIOGRAFÍA}

Alea, una retrospectiva crítica. Selección, prólogo y notas de Ambrosio Fornet. La Habana: Letras Cubanas, 1987.

Beverley, John. Subalternity and Representation: Arguments in Cultural Theory. Durham: Duke University Press, 1999.

“Calibán después del comunismo”. Roberto Fernández Retamar y los estudios latinoamericanos. Elzbieta Sklodowska y Ben A. Heller, eds. Pittsburgh: IILI, 2000. 117-33.

Deleuze, Gilles y Félix Guattari. Mil mesetas. Valencia: Pre-textos, 1997.

Evora, José Antonio. Tomás Gutiérrez Alea. Madrid: Cátedra, 1996.

Gutiérrez Alea, Tomás. Dialéctica del espectador. La Habana: Cuadernos de la revista Union, 1982.

Hardt, Michael. Gilles Deleuze: An Apprenticeship in Philosophy. Minneapolis: University of Minnesota Press, 1993.

Kojeve, Alexandre. Introduction to the Reading of Hegel. New York: Basic Books, 1969.

La última cena. Dir. Tomás Gutiérrez Alea. La Habana: Instituto Cubano de Arte e Industria, Center for Cuban Studies, 1976.

Linebaugh, Peter y Marcus Rediker. The Many-Headed Hydra: Sailors, Slaves, Commoners, and the Hidden History of the Revolutionary Atlantic. Boston: Beacon Press, 2000. 
Montag, Warren. Bodies, Masses, Power: Spinoza and his Contemporaries. London: Verso, 1999.

Montejo, Esteban. Biografía de un cimarrón. Barcelona: Ariel, 1968.

Negri, Antonio. The Savage Anomaly: the Power of Spinoza's Metaphysics and Politics. Minneapolis: University of Minnesota Press, 1991.

y Michael Hardt. Empire. Cambridge: Harvard University Press, 2000.

Oroz, Silvia. Tomás Gutiérrez Alea: los filmes que no filmé. La Habana: Unión de Escritores y Artistas de Cuba, 1989.

Ortiz, Fernando. Contrapunteo cubano del tabaco yel azúcar. Madrid: Edito CubaEspaña, 1999.

Patton, Paul. Deleuze and the Political. London \& New York: Routledge, 2000.

Sklodowska, Elzbieta y Ben A. Heller (Eds.). Roberto Fernández Retamar y los estudios latinoamericanos. Pittsburgh: IILI, 2000.

Tomás Gutiérrez Alea: poesía y revolución. Islas Canarias: Filmoteca Canaria, 1994.

Virno, Paolo y Michael Hardt. Radical Thought in Italy. Minneapolis: University of Minnesota Press, 1996.

West, Dennis. “Esclavitud y cine en Cuba: el caso de 'La última cena’”. Tomás Gutiérrez Alea: poesía y revolución. Islas Canarias: Filmoteca Canaria, 1994. 